\title{
Hvordan kan sykehusene få bedre resultater?
}

\author{
Sykehussektoren er i dårligere forfatning enn mange tror. Sykehusene \\ drives med store underskudd, behandlingskøene vokser, vi har dår- \\ ligere overlevelse for mange kreftsykdommer enn i sammenliknbare \\ land og - kanskje det mest illevarslende - norsk helsevesen sikrer ikke \\ likhet. Det finnes ingen klar oppskrift på løsning. Lite tyder på at proble- \\ met er mangel på ressurser. Knapt noe europeisk land bruker mer \\ penger på helsevesenet enn Norge. Vi foreslår her en fempunktsplan \\ for å rette på situasjonen.
}

\section{Åge Danielsen}

Wedel Jarlsbergs vei $15 \mathrm{~A}$

$1358 \mathrm{Jar}$

\section{Terje P. Hagen}

Institutt for helseledelse og helseøkonomi

Universitetet i Oslo

Rune J. Sørensen

rune.sorensen@bi.no

Handelshøyskolen BI

Nydalsveien 37

0442 Oslo

For brukerne er det viktigste kjennetegn på kvaliteten av helsetjenestene at de er tilgjengelige i tilstrekkelig omfang uten lange ventetider. Vurdert på denne måten ble kvaliteten forbedret fra 2000 og videre de første årene etter sykehusreformen av 2002. Forklaringen er først og fremst innføring av innsatsstyrt finansiering av sykehusene fra 1997. Men fallet i gjennomsnittlig ventetid stoppet opp med synkende refusjon for diagnoserelaterte grupper (DRG) og har økt svakt de siste årene.

Det er de siste årene blitt mer oppmerk- somhet omkring servicekvalitet. Tilbakemeldinger fra pasientene registreres jevnlig og viser gjennomgående høy tilfredshet med behandling og pleie. Det har også vært lagt vekt på andre serviceindikatorer, bl.a. hvor lang tid det tar før det foreligger epikrise etter sykehusoppholdet. Slike indikatorer har vist at det har vært forbedringer i tjenestene de siste årene, men det er fortsatt mye å hente.

Det kan derimot ikke sies at den medisinske kvaliteten er blitt systematisk fulgt opp. På noen områder, bl.a. innenfor kreftbehandlingen, er kvalitetsforskjellene mellom sykehusene godt dokumentert (1). Det samme gjelder forskjeller i kvalitet for enkelte sykdomsgrupper mellom Norge og andre land med avansert helsetjeneste, målt ved overlevelse (2). Det gjøres lite for å forklare hva som skaper variasjoner i medisinsk kvalitet, og det settes i liten grad inn systematiske tiltak for kvalitetsforbedring. I andre land giøres analyser av slike forhold med utgangspunkt i medisinske kvalitetsregistre. I Norge finnes det få registre, og opplysningene utnyttes dårlig.

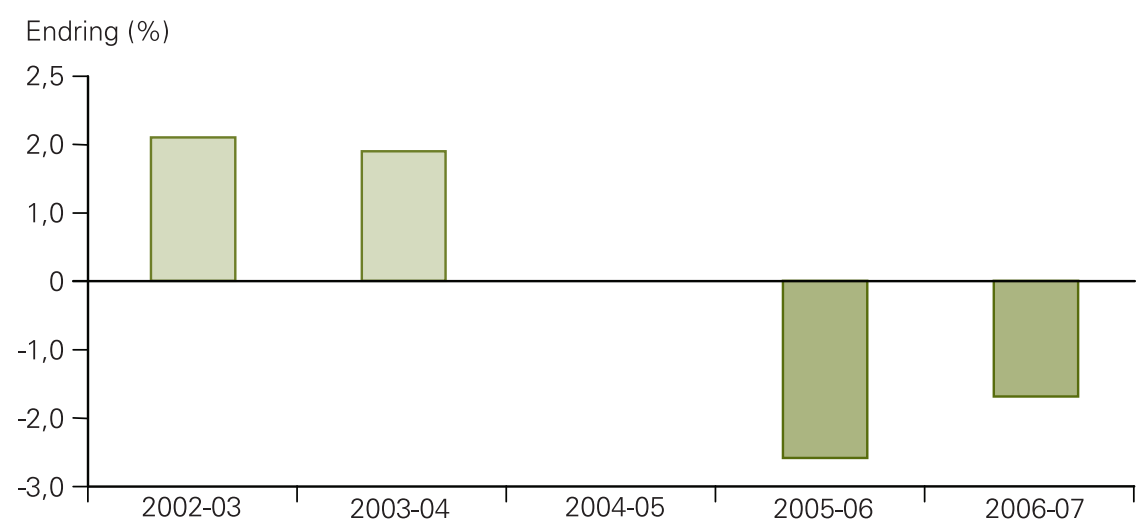

Figur 1 Produktivitetsøkning (+) og produktivitetsnedgang (-) målt som prosentvis endring i driftskostnad per korrigerte opphold på landsbasis. Bearbeidelser basert på Samdata (1)

\section{Effektivitet}

Kostnadseffektiviteten i sykehusene i Norge er klart lavere enn i Finland og noe lavere enn i de andre nordiske landene (3). Kostnadseffektiviteten gikk trolig noe opp de første årene etter sykehusreformen, men er nå fallende (fig 1). Flere internasjonal studier, blant annet Euro Health Consumer Index 2007 (4), viser at Norge rangeres lavt når det gjelder spørsmålet om hvor mye og hvor gode helsetjenester vi får igjen for pengene. Sykehusreformen skulle sikre enhetlig eierskap og helhetlig styring. I dag vet vi at dette var en stor reform med små resultater.

Årsakene til lav effektivitet er sammensatte, men mye må tilskrives en oppsplittet og lite rasjonell sykehusstruktur. Det finnes grupper av lokalsykehus innenfor små geografiske områder, noe som gir høye kostnader i forbindelse med vaktordninger og beredskap.

Manglende samordning av drift, beredskap og investeringer i Oslo-området har vært et annet stort problem.

Men det skjer effektivitetsforbedringer i sykehusene: Bedre anestesi og utvikling av minimalt invasive operasjonsteknikker gir kortere rekonvalesensperiode, nye medikamenter kan tas hjemme i stedet for ved innleggelse, nye organisasjonsformer bidrar til strømlinjeforming, nærmest industrialisering, av sykehusenes aktiviteter. Felles for disse endringene er at de stort sett er drevet frem av teknologiske endringer, og at de ofte krever investeringer for å kunne gi uttelling.

\section{Fordeling}

En del av regjeringens begrunnelse for sykehusreformen var større likhet $i$ helsetilbud. Samtidig vet vi at kreftoverlevelsen varierer med utdanningsnivå (5). Det er betydelige geografiske ulikheter i innbyggernes forbruk av somatiske spesialisthelsetjenester (6). I perioden 1999-2005 er avviket fra landsgjennomsnittet på helseregionnivå maksimalt 2,5-3\% etter kontroll for variasjoner i behov, mens ulikheten innad $i$ regionene er større. Det er ingen tegn til at forskjellene blir mindre. Prioriteringen av yrkesaktive sykmeldte gjennom egne betalingsordninger bidrar heller ikke til at å fremme likhet.

\section{En plan i fem punkter}

Reformer må gjøres med utgangspunkt $i$ to prinsipper: 


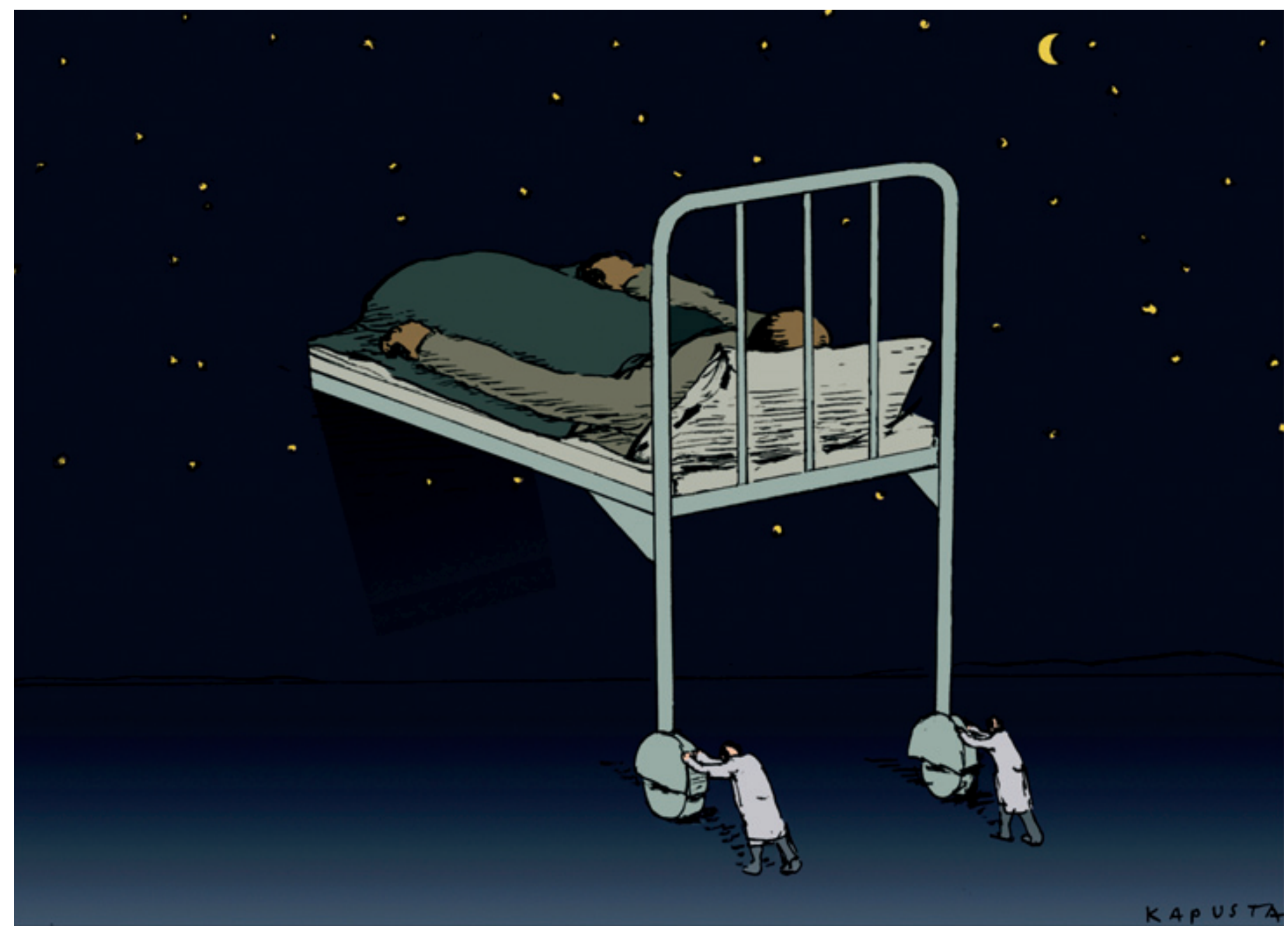

Illustrasjonsfoto @ Images.com/Corbis/SCANPIX

- Vi må bygge opp en helsetjeneste som holder pasientene ute av sykehusene så lenge som mulig

- Når pasienten kommer til sykehuset, må han/hun bli møtt av bedre kvalitet og høyere kostnadseffektivitet enn i dag

Norge har en av verdens mest sentraliserte styringsmodeller. Det meste kan ankes opp til statsrådens bord. Til og med småsaker, f.eks. ferielukking av en avdeling ved et mindre sykehus, presses oppover i styringssystemet av mediene, pasientorganisasjonene og tillitsvalgte. Stortinget vil imidlertid videreføre hovedtrekkene i dagens modell. Våre forslag tar utgangspunkt det.

\section{Bedre informasjon}

For det første må pasienter, fastleger og myndigheter få bedre tilgang på informasjon om hvilke sykehus som tilbyr høy kvalitet. Første betingelse er at det utvikles kvalitetsregistre for de viktigste sykdomsgruppene. I Norge har slike registre vært diskutert lenge, men lite er gjort. Kreftregisteret er ett av få unntak. Vi mangler fortsatt kvalitetsregistre for hjerte- og karsykdommer, leddsykdommer, lungesykdommer osv. Neste betingelse er at disse registerdataene blir analysert. Når dette er på plass, kan informasjon tilflyte de viktige beslutningstakerne, som er pasienter, fastleger og myndigheter. Som i utlandet bør vi diskutere økonomiske sanksjoner mot sykehus med dårlig kvalitet.

I dag er journalsystemene i helsetjenesten svakt integrert. Problemene mellom sykehusene er i ferd med å bli mindre, mens det mellom primærhelsetjenesten og spesialisthelsetjenesten fortsatt er tette skott. Det har vært politisk uvilje mot å lette på restriksjoner for å gjøre integrasjon mulig. Argumentet har vært personvernhensyn, primært at informasjon kan komme på avveier. Vi kan ikke se at personvernet bør være til hinder for vesentlig bedre elektronisk informasjonsutveksling mellom primær- og spesialisthelsetjenesten.

\section{Klarere prioriteringer}

Effektivitetsutviklingen i sykehusene har ikke holdt tritt med behovsutviklingen, og selv med fortsatt store økninger i offentlige bevilgninger må det prioriteres. Dette skal i dag skje med grunnlag i Lønning-utvalgenes kriterier. Disse er for generelle og har liten praktisk nytteverdi. Myndighetenes omfattende tilsagnsbrev er heller ikke til særlig hjelp. Svært mye skal prioriteres høyt, lite skal prioriteres lavt.

I praksis er det sykehusledelsen og behandlingsansvarlig lege som avgjør hvem som skal få hvilken behandling. Dette fører til mye tilfeldigheter: Noen sykdommer blir vurdert som ikke-behandlingsverdige ved noen sykehus, men blir behandlet ved andre, kostbare og livsforlengende medisiner gis ved ett sykehus, ikke ved et annet, «lette» behandlinger kan bli utført ved ett sykehus, ikke et annet sted osv. Med støtte fra aktive klinikere på de ulike områder kan bedre nasjonale retningslinjer etableres. Dette er en oppgave som burde vært politisk høyt prioritert. Slik kan man dempe den «controller»-styring som i dag synes å være hovedsaken både i Helsedepartementet og $i$ den regionale forvaltning.

I enkelte land har man etablert forsikringsordninger for behandlinger som fellesskapet ikke tar ansvar for. En myndighetsorganisert eller kontrollert forsikringsordning er et bedre alternativ enn å la underskuddene vokse eller køene bli lengre. I Norge er det trolig mer aktuelt å øke egenbetalingen noe, kanskje ved innføring av pasientbetaling for hotellfunksjonene ved sykehusene. Også pasientbetalingen 


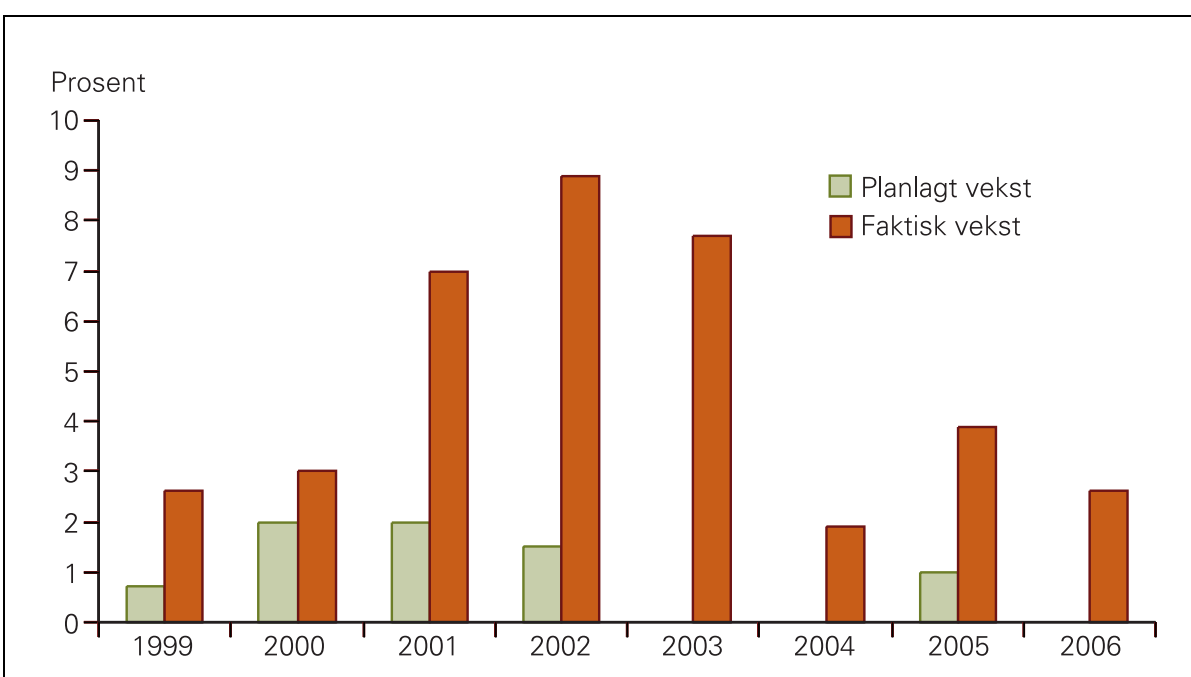

Figur 2 Planlagt og faktisk aktivitetsvekst målt i DRG-poeng (8)

ved poliklinikkene bør man tenke igjennom.

Mer sentralisering og mer desentralisering Norsk bosettingsmønster krever desentraliserte tilbud. Folks behov for trygghet er en grunnleggende premiss i helsepolitikken. Samtidig har utviklingen i moderne medisin et sterkt sentraliserende preg. Spesialister vil arbeide der de får utnyttet og utviklet sin kompetanse. Frekvensen av mange sykdommer er også relativt lav, spesialistkompetansen må derfor konsentreres. Det er godt dokumentert at for stor spredning av høyspesialisert medisin med tilhørende lavt behandlingsvolum gir til dels betydelig forringelse av kvaliteten (7). Primærleger, legesentre, utnyttelse av informasjonsteknologi sammen med gode kommunikasjoner til mer spesialiserte institusjoner må kunne dekke trygghetsbehovet sammen med forvissningen om rask behandling ved de spesialiserte sykehusene.

Nøkkelen til en både effektiv og høyt kvalifisert sykehusbehandling ligger $i$ avveiningen mellom desentralisert og sentralisert behandling. Ett element er forbedring av kommunehelsetjenesten. Samhandlingsproblemene, som man er opptatt av for tiden, er trolig diagnosespesifikke. Det er snakk om kapasitets- og kompetanseproblemer (rusbehandling), mer bruk av fastleger (astma og diabetes), bedre kompetanse og mer pasientopplæring (geriatri). Fastlegenes frie stilling bør vurderes. Kanskje bør de være ansatt på regionalt nivå, som i Sverige og Danmark, eller kommunalt ansatte $i$ stedet for private næringsdrivende på kontrakt med kommunen, som i dag? De internasjonale erfaringene med de ulike organisasjonsmodeller er ikke entydige, og vi foreslår å eksperimentere med forskjellige løsninger. La oss prøve ut ulike modeller for fastlegenes organisering i en femårsperiode og evaluere effektene.

\section{Privatisering}

De første årene etter tusenårsskiftet innebar en økning i bruken av private sykehus. Dette gjaldt primært innen enklere dagkirurgisk behandling. Ekspansjonen innen offentlig finansiert og privat utført dagkirurgi var kanskje den viktigste enkeltårsak til fallet i ventetidene i perioden 2001-03. Som følge av hardere konkurranse tilbyr de private sykehusene stadig lavere priser. De siste årene er bruken av de private sykehusene blitt redusert, noe som har bidratt til lengre ventelister. Argumentet var at de offentlige sykehusene manglet pasienter. Det er vanskelig å se logikken.

Vi mener myndighetene bør legge til rette for at de små private sykehusene kan vokse på de feltene der de er effektive, primært innenfor enklere kirurgi. Samtidig må erfaringene som er høstet med konkurranseutsetting overføres til andre felter. Den offentlig finansierte og privat drevne laboratorie- og røntgenvirksomheten er et slikt område. Også private avtalespesialister bør i høyere grad utsettes for konkurranse og avgrensede kontraktsperioder.

\section{Bedre økonomistyring}

Finansieringssystemet for sykehusene har vært en hengemyr. De siste ti årene har de vært finansiert ved én rammekomponent og én aktivitetsbasert komponent. Sykehusansatte har stort sett basert seg på en tenkning der man forutsetter at inntekten på marginen (den aktivitetsbaserte komponenten) dekker merkostnadene. Man har sett bort fra signalene man har fått om aktivitetsvekst. Dette har ledet til langt høyere aktivitetsvekst enn planlagt (fig 2) (8), store underskudd og tilleggsbevilgninger.

Finansieringsmodellen bør hvile på to bærebjelker. For det første må staten klart definere et ønsket aktivitetsnivå det påfølgende året. Derfor bør den aktivitetsbaserte komponenten avgrenses. Den må gis et knekkpunkt når aktiviteten går en viss pro- sentandel utover det ønskede (9). For det andre må det legges opp til en realistisk budsjettvekst. Som figur 2 viser har man de fleste årene stort sett planlagt for nullvekst. Det har ikke vært realistisk.

\section{Veien videre}

Nyere studier viser også at forbedringer $i$ helsetjenestene har hatt vesentlig betydning for levealderen (10). Men vi burde i Norge gjort det enda bedre, bl.a. som følge av sunnere livsstil. Vi burde fått mer ut av helsevesenet i form av bedre helse og høyere levealder. Etter vår mening er det tre forhold som gjør det vanskelig å reformere og styre norsk helsevesen.

For det første har det vært en dominerende forestilling om at «Norge har verdens beste helsevesen». Å påstå noe annet har vært politisk ukorrekt kritikk av hardtarbeidende leger og sykepleiere. Men uten en erkjennelse av at andre håndterer helsevesenet bedre enn vi gjør i Norge er det vanskelig å komme videre. For det andre er det politisk krevende å etablere en rasjonell sykehusstruktur. Til tross for vesentlig kortere reisetider og godt dokumenterte kvalitetsproblemer ved mange lokalsykehus er det gjort for lite for å organisere en god arbeidsdeling. For det tredje er det ingen offentlig sektor folk flest prioriterer høyre enn helsesektoren. Høy inntektsvekst har kamuflert effektivitets- og kvalitetsproblemene. Smertefulle reformer og effektivitetsforbedring gjennomføres først når alle ser at det ikke er noen vei utenom.

Oppgitte interessekonflikter: Ingen

\section{Litteratur}

1. Samdata-rapport. www.sintef.no/SAMDATA (12.1.2009)

2. Armesto SG, Lapetra MLG, Wei L et al. Health care quality indicators project 2006. Data collection update report. OECD Health Working Papers No. 29. Paris: OECD, 2006

3. Linna M, Häkkinen U, Magnussen J. Comparing hospital cost efficiency between Norway and Finland. Health Policy 2003; 77: 268-78.

4. Health Consumer Powerhouse. Euro Health Consumer Index 2007. www. healthpowerhouse.com/ (12.1.2009).

5. Kravdal $\varnothing$. Does place matter for cancer survival in Norway? A multilevel analysis of the importance of hospital affiliation and municipal socio-economic resources. Health Place 2006; 12: 527-37.

6. Nerland SM, Hagen TP. Forbruk av spesialisthelsetjenester: ble det større likhet etter sykehusreformen? Tidsskrift for samfunnsforskning 2008; 49: $37-72$.

7. Norderhaug I, Krogstad U, Ingebrigtsen T et al. Pasientvolum og behandlingskvalitet. Rapport nr 102007. Oslo: Nasjonalt kunnskapssenter for helsetjenesten, 2007.

8. Tjerbo T, Hagen TP. Deficits, soft budget constraints and bailouts: budgeting after the Norwegian hospital reform. Scandinavian Political Studies 2009. http: //www3.interscience.wiley.com/ journal/121392370/issue (17.3.2009).

9. Norges offentlige utredninger. Behovsbasert finan siering av spesialisthelsetjenesten. NOU 2003: 1

10. Or Z. Exploring the effects of health care on mortality across OECD countries. OECD Labour Market and Social Policy Occasional Papers, no. 46, 2001. Paris: OECD, 2001 